\title{
Perioperative SARS-CoV-2 Infection in Patients Undergoing Elective Surgery in Gynecology Clinic: Tertiary Center Experience
}

\author{
Gulnihal Reyhan TOPTAS1, Eylem UNLUBILGIN'1, Tugba KINAY1, Sezin Erturk AKSAKAL ${ }^{1}$, Mehmet Akif AKGUL ${ }^{1}$

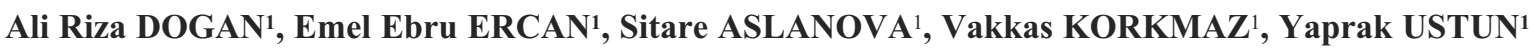

Ankara, Türkiye

\section{ABSTRACT}

OBJECTIVE: The objective of this study was to determine the incidence of perioperative "severe acute respiratory syndrome coronavirus-2 (SARS-CoV-2)" infection among women, operated during Coronavirus disease-2019 (COVID-19) era.

STUDY DESIGN: All patients who were operated on between March 11, 2020, and December 31, 2020 , in our gynecology clinic were included in this cross-sectional study. The clinical and demographic characteristics of the patients, preoperative and postoperative SARS-CoV-2 positivity, the progress of the infection, and the survival rates in positive cases were analyzed. COVID-19 cases were diagnosed by reverse transcription-polymerase chain reaction testing for SARS-CoV-2.

RESULTS: Operations of 133 (33\%) of 406 patients were canceled for various reasons. 275 patients were operated on. Preoperatively three patients were diagnosed with COVID-19. One of these patients died and two were operated on after treatment and self-isolation. Only one $(0.4 \%)$ patient was diagnosed with COVID-19 30 days postoperatively and completely recovered. We calculated the perioperative SARS-CoV-2 positivity rate as 1.4\% (276 surgeries were planned and 4 patients were diagnosed with COVID-19). During the study, 107 physicians worked in our clinic alternately. Two (1.8\%) of these physicians were diagnosed with COVID-19 and completely recovered without the need for intensive care. In addition, nine patients who were previously diagnosed with COVID-19 were operated on. Postoperative respiratory and other system complications did not occur in nine patients, previously diagnosed with COVID-19.

CONCLUSION: The results of our study show that gynecological surgical procedures do not increase the transmission and mortality rates of SARS-CoV-2 among patients and healthcare professionals as long as infection control measures are followed.

Keywords: Coronavirus infection, Gynecological surgery, Health care, Perioperative period, Triage

Gynecol Obstet Reprod Med 2022;28(2):164-171

${ }^{1}$ Etlik Zubeyde Hanim Maternity \& Women's Health Teaching and Research Hospital, Department of Gynecology, Ankara, Türkiye

Address of Correspondence: Gülnihal Reyhan Toptas Department of Gynecology, Etlik Zubeyde Hanim Women's Health Training and Research Hospital, Faculty of Medicine, University of Health Sciences, Ankara, Türkiye

gulnihalreyhan@gmail.com

Submitted for Publication: 30.03.2021 Revised for Publication: 28.04.2021 Accepted for Publication: 14.08.2021 Online Published: 13.09.2021

ORCID IDs of the authors: EU: 0000-0002-1529-2523 SEA: 0000-0002-4418-7319 ARD:0000-0003-4845-3044 SA: 0000-0003-3388-8221 $Y U: 0000-0002-1011-3848$

\begin{tabular}{|c|c|}
\hline \multirow{3}{*}{ 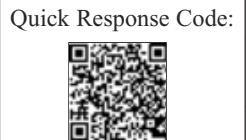 } & Access this article online \\
\hline & $\begin{array}{l}\text { Website: www.gorm.com.tr } \\
\text { e- mail: info@gorm.com.tr }\end{array}$ \\
\hline & DOI:10.21613/GORM.2021.1206 \\
\hline
\end{tabular}

How to cite this article: Toptas GR. Unlubilgin E. Kinay T. Aksakal SE. Akgul MA. Dogan AR. Ercan EE. Aslanova S. Korkmaz V. Üstün Y. Perioperative SARS-CoV-2 Infection in Patients Undergoing Elective Surgery in Gynecology Clinic: Tertiary Center Experience. Gynecol Obstet Reprod Med. 2022;28(2):164-171

(cc) BY

\section{Introduction}

In December 2019, in Wuhan city, Hubei province, China, a series of pneumonia cases similar to viral pneumonia but unknown etiology were noted (1). The causative agent of pneumonia was determined to be a new coronavirus, called severe acute respiratory syndrome coronavirus 2 (SARS-CoV-2) (2). World Health Organization (WHO) named the disease caused by SARS-CoV-2 as coronavirus disease 2019 (COVID-19) in February 2020 (3). COVID-19, which caused the death of more than 4000 people until 11 March 2020, spread rapidly over countries, was officially declared as a pandemic by WHO on the same date (4). The pandemic has put enormous pressure on health systems around the world (5). The health systems worldwide, which were not prepared for a pandemic, have determined policies specific to each country and region and started to implement measures to increase the capacity of intensive care services $(6,7)$. The authorities have emphasized that some of the patients who still need medical care can be treated at a time when the impact of COVID-19 on the health system will decrease, and some surgical procedures can be 
canceled (8). Health systems and health care workers have faced great difficulties and surgical departments have also been affected by this situation. Preparations for the pandemic are primarily focused on increasing the capacity of intensive care for severely ill patients and provide adequate protective equipment for medical staff (9). American College of Surgeons (ACS) recommended that procedures for adnexal torsion, tubal-ovarian abscess rupture, acute-severe vaginal bleeding, tuboovarian abscess (resistant to medical treatment), abortus and ectopic pregnancy, cerclage, cesarean, and oncologic surgery should not be postponed and performed immediately. Other procedures like sterilization, myomectomies, and hysterectomies (with an indication of myoma), endometriosis, chronic pelvic pain, adnexal mass surgery (considered to be benign), pelvic prolapse, and incontinence surgery can be postponed (10).

WHO acknowledged that most of the world's health systems and services are inadequate and has published guidelines on how countries will maintain essential healthcare services during the COVID-19 pandemic (11). In our country, to reduce the workload in hospitals and to continue the health services, The Ministry of Health-Türkiye has decided to postpone all elective surgery on March 17, 2020 (12). Policies for the COVID-19 pandemic have been determined; a guideline containing measures and recommendations for the management of cases, examination, and protection of healthcare personnel, has been published considering the surgeries that cannot be postponed such as emergency surgery and oncological surgery (13). Regarding the treatment of patients without COVID-19, it was recommended that each clinic should identify priority cases in addition to emergency surgical cases. It was planned to provide personal protective equipment (PPE) to the employees and to use them correctly. It was emphasized that everyone in the hospital (employee, student, patient, attendant) should wear a mask during their stay. In addition, it has been suggested not to accept an accompanying person in services and to limit them to at most one person if required. Probable/certain COVID-19 patients should be admitted to the COVID-19 services, following standard droplet and contact isolation advice (13).

The triage of patients with suspected infection in hospitals is important. COVID-19 is diagnosed with clinical symptoms such as fever, fatigue, dry cough, pneumonia, headache, diarrhea, hemoptysis, respiratory distress, rhinorrhea, and radiological findings; laboratory tests confirm the diagnosis (14). Real-time reverse transcription-polymerase chain reaction (RT-PCR) of viral nucleic acid is considered one of the diagnostic tests (15). According to the Ministry of Health-Türkiye guidelines, if testing for COVID-19 is required, the sample should be taken at least 48 hours before the procedure; surgery should be performed as soon as possible after the hospitalization (on the same day if possible), and the pre-and post-procedure periods should be kept short (13).
In our study, we performed surgeries of patients who cannot be postponed or do not agree to be postponed and we aimed to determine the incidence of perioperative SARS-CoV-2 positivity among women, operated during the COVID-19 era.

\section{Material and Method}

All patients who were operated on between March 11, 2020, and December 31, 2020, at the Gynecology Clinic of Etlik Zubeyde Hanim Gynecology Training and Research Hospital, were included in this cross-sectional study. The data were collected by scanning patient files and the database of the institution and the Ministry of Health. All participants signed informed written consent before being enrolled in the study. The study was reviewed and approved by the ethics committee of Etlik Zubeyde Hanim Gynecology Training and Research Hospital (Ethics approval reference number: 2021/64 date:09.06.2021). All procedures were performed according to the Declaration of Helsinki. Surgical procedures such as endometrial/cervical curettage, hysteroscopy, conization/Loop Electrosurgical Excision Procedure (LEEP), and vaginal cyst excision were excluded from the study due to the short duration of surgical procedure and hospital stay.

Priority and emergency cases were determined with a triage system. Postponable cases were followed up during the pandemic period without being operated and their treatments were arranged. The planned operations of patients who did not accept COVID-19 comorbidity wanted to be operated in another hospital, decided to be operated in a multidisciplinary hospital, had SARS-CoV-2 PCR (+), or had a history of COVID-19 contact were canceled. Operations of patients who cannot be postponed or those who do not agree to be postponed have been performed. Treatment-resistant uterine bleeding, endometrial hyperplasia/intraepithelial neoplasia/ endometrial ca, pelvic organ prolapses (presenting with the complaint of recurrent urinary tract infection, not benefiting from pessary), symptomatic and faster-growing myomas, adnexal masses (with suspicion of malignancy), and acute pelvic pain were considered urgent and were not postponed. Total abdominal hysterectomy (TAH)+/-bilateral salpingooophorectomy (BSO), total laparoscopic hysterectomy +/$\mathrm{BSO}$, vaginal hysterectomy +/- BSO, ovarian cystectomy, myomectomy, unilateral salpingo-oophorectomy, ovarian detorsion, sacrohysteropexy, trans-vaginal-tape (TVT) operation, anterior-posterior repair+perineoplasty, radical hysterectomy+BSO+bilateral pelvic paraaortic lymph node dissection (BPPLND), TAH+BSO+BURCH, tuboovarian abscess surgery and stating surgery were the operations performed. The patients who underwent TVT operation did not accept the postponement of the operation and stated that their quality of life was severely impaired.

Identity information, age, body mass index (BMI), gravida, parity, additional disease, smoking, complaint, surgery indica- 
tion, surgery performed, type of anesthesia, presence of postoperative transfusion, hospitalization duration, post-operative complications, pre-operative and post-operative SARS-CoV-2 PCR results, hospital or homestay in case of SARS-CoV-2 positivity, recovery/intensive care unit admission/ survival rates in SARS-CoV-2 positive patients and the treatment received was recorded and analyzed retrospectively.

We defined one day before and 30 days after surgery as the perioperative period (the day of surgery was defined as day 0 ). The preoperative SARS-CoV-2 positivity was screened with reverse transcription-polymerase chain reaction (RT-PCR) one day before the surgery and the patients were hospitalized to be operated on the next day. After their hospitalization, preoperative reassessment was made with internal medicine and anesthesia doctors. In the postoperative one-month period, if SARS-CoV-2 was detected positive by RT-PCR, it was confirmed by the database of the Turkish Ministry of Health. The primary outcome measure for patients was the positivity of RT-PCR. Hospitalization of patients with positive tests need for intensive care unit admission, the number of days in intensive care if recovered, treatment, and 30-day mortality were evaluated.

All statistical tests were performed using the Statistics Package for the Social Sciences (SPSS) program (version 21, SPSS, Inc, Chicago, IL). The median, minimum, and maximum values of the data and the numbers and rates of the categorical data were calculated with descriptive statistics tests.

\section{Results}

During the study period, 406 patients were re-evaluated preoperatively with internal medicine and anesthesiologists after their hospitalization. After the evaluation, the operation of 16 patients who did not accept COVID-19 comorbidity was postponed, six patients decided to be operated on in another hospital, 14 patients could not be operated on because it was advised for the operation to take place in a multidisciplinary hospital. Three patients with preoperative SARS-CoV-2 PCR positivity and one patient with a history of COVID-19 contact were detected. 59 operative hysteroscopy, one diagnostic hysteroscopy, five vaginal cyst excision, 19 dilations and curettage, five conization/LEEP procedures were excluded. The medical information of four patients could not be reached. Finally, 275 of the patients who were operated on during the COVID-19 pandemic, were analyzed (Figure 1).

The clinical characteristics and demographic data of the patients are shown in table I.

The median age was 46 (24-76 years), BMI 30 (20-42), gravida $3(0-10)$, parity $2(0-8) .64(23.3 \%)$ of the operated patients were smokers, 174 of $(63.3 \%)$ patients had no additional disease. The most common complaints were abnormal uterine bleeding (36\%) and pelvic pain (37\%).

The indication for surgery, type of surgery, type of anesthesia, need for transfusion, the period of hospital stay, complications, and postoperative SARS-CoV-2 positivity is shown in table II.

\begin{tabular}{|c|c|c|}
\hline \multirow{12}{*}{$\begin{array}{l}\text { Patients } \\
\text { scheduled } \\
\text { to be } \\
\text { operated } \\
\text { in the } \\
\text { gynecology clinic on } \\
\text { March } 11,2020 \text { - } \\
\text { December } 31,2020, \\
n=406\end{array}$} & \multirow{5}{*}{$\begin{array}{l}\text { Patients whose } \\
\text { operation is canceled } \\
\text { or delayed, } \\
n=40\end{array}$} & Patients in need of a multidisciplinary hospital, $n=14$ \\
\hline & & Pre-operative SARS-Cov-2 PCR* Positive patients, \\
\hline & & Patients in contact with COVID-19**, $n=1$ \\
\hline & & Patients who do not accept COVID-19 comorbidity, \\
\hline & & \multirow[t]{2}{*}{ Patients who want to be operated in another hospital } \\
\hline & \multirow{6}{*}{$\begin{array}{l}\text { Patients who were } \\
\text { operated but } \\
\text { excluded from the } \\
\text { study, } \\
n=93\end{array}$} & \\
\hline & & Operative hysteroscopy, $\mathrm{n}=1$ \\
\hline & & Dilation and curettage, $\mathrm{n}=19$ \\
\hline & & Conization/LEEP $P^{* * *}, \mathrm{n}=5$ \\
\hline & & Vaginal cyst operation, $n=5$ \\
\hline & & Medical information unavailable, $\mathrm{n}=4$ \\
\hline & & Operated, $\mathrm{n}=275$ \\
\hline
\end{tabular}

Figure 1: Flow chart of the study

*SARS-CoV-2 PCR: polymerase chain reaction testing for severe acute respiratory syndrome coronavirus-2 ${ }^{* *}$ COVID-19: Coronavirus Disease-2019 ${ }^{* * *}$ LEEP: Loop Electrosurgical Excision Procedure 
Table I: Demographic and clinical characteristics of the study group

\begin{tabular}{|c|c|}
\hline Characteristics & $\mathrm{n}=275$ \\
\hline Age, median (range), years & $46(24-76)$ \\
\hline BMI, median (range), kg/m2 & $30(20-42)$ \\
\hline Gravida, median (range) & $3(0-10)$ \\
\hline Parity, median (range) & $2(0-8)$ \\
\hline \multicolumn{2}{|l|}{ Smoke, number, \% } \\
\hline No & $211(76.7)$ \\
\hline Yes & $64(23.3)$ \\
\hline \multicolumn{2}{|l|}{ Additional Disease, number, $\%$} \\
\hline No & $174(63.3)$ \\
\hline $\mathrm{HT}$ & $31(11.3)$ \\
\hline HT+DM & $7(2.5)$ \\
\hline $\mathrm{HT}+\mathrm{DM}+\mathrm{Chronic}$ Lung Disease & $1(0.4)$ \\
\hline $\mathrm{HT}+\mathrm{Chronic}$ Lung Disease & $3(1.1)$ \\
\hline HT+Hypothyroidism & $1(0.4)$ \\
\hline Arrhythmia & $3(1.1)$ \\
\hline Breast Cancer & $2(0.7)$ \\
\hline Fibromyalgia & $1(0.4)$ \\
\hline Rheumatoid Arthritis & $1(0.4)$ \\
\hline Valvular Heart Disease & $1(0.4)$ \\
\hline Thyroid Cancer & $1(0.4)$ \\
\hline Hepatitis B & $1(0.4)$ \\
\hline Tuberculosis & $1(0.4)$ \\
\hline Schizophrenia & $1(0.4)$ \\
\hline $\mathrm{DM}$ & $9(3.3)$ \\
\hline Chronic Lung Disease & $8(2.9)$ \\
\hline Migraine & $3(1.1)$ \\
\hline Hypothyroidism & $20(7.3)$ \\
\hline Hepatitis C & $1(0.4)$ \\
\hline Panic Disorder & $4(1.5)$ \\
\hline Obsessive-Compulsive Disorder & $1(0.4)$ \\
\hline \multicolumn{2}{|l|}{ Complaint, Number, \% } \\
\hline No & $2(0.7)$ \\
\hline AUB & $136(49.0)$ \\
\hline AUB+Urinary Incontinence & $1(0.4)$ \\
\hline Pelvic Organ Prolapse & $29(11)$ \\
\hline Pelvic Pain & $102(37.0)$ \\
\hline Urinary Incontinence & $4(1.5)$ \\
\hline Bleeding After Caesarean & $1(0.4)$ \\
\hline
\end{tabular}

HT: Hypertension, DM: Diabetes Mellitus, AUB: Abnormal uterine bleeding

While the most common indications were uterine bleeding due to myoma uteri (41.8\%), pain due to pelvic mass $(20.4 \%)$, and pelvic organ prolapse $(10.9 \%)$; the operations performed most frequently were TAH+BSO $(25 \%, 1)$, TAH $(16.7 \%)$ and TLH (10.5\%). In the postoperative period, only $1(0.4 \%)$ patient had SARS-CoV-2 infection (Table II).

After the SARS-CoV-2 PCR positivity was confirmed, the operations of three patients were canceled on the first day before the surgery. In one of three patients with pre-operative SARS-CoV-2 PCR positivity, sudden cardiac death/exitus developed on the 5 th day after the diagnosis of COVID-19, al-
Table II. Surgical characteristics of the study group.

\begin{tabular}{|c|c|}
\hline Characteristics & $\mathrm{n}=\mathbf{2 7 5}$ \\
\hline \multicolumn{2}{|l|}{ Surgery indication, number, $\%$} \\
\hline Endometrial cancer & $7(2.5)$ \\
\hline Complex endometrial hyperplasia with atypia & $2(0.7)$ \\
\hline BRCA mutation, risk reduction surgery & $2(0.7)$ \\
\hline Cervical cancer & $1(0.4)$ \\
\hline Arteriovenous malformation & $1(0.4)$ \\
\hline Pelvic organ prolapse & $30(10.9)$ \\
\hline Pelvic pain+pelvic mass & $56(20.4)$ \\
\hline Tuba-ovarian abscess & $17(6.2)$ \\
\hline Myoma uteri+Treatment-Resistant Bleeding & $115(41.8)$ \\
\hline Urinary Incontinence & $4(1.5)$ \\
\hline Ovarian Torsion & $11(4)$ \\
\hline MTRB & $16(5.8)$ \\
\hline MTRB+urinary incontinence & $1(0.4)$ \\
\hline Endometrial Intraepithelial Neoplasia & $12(4.4)$ \\
\hline \multicolumn{2}{|l|}{ Type of Surgery, number, $\%$} \\
\hline Myomectomy & $18(6.5)$ \\
\hline Tuba ovarian Abscess Surgery/Laparoscopy & $10(3.6)$ \\
\hline Tuba ovarian Abscess Surgery/Laparotomy & $6(2.2)$ \\
\hline Unilateral Salpingooophorectomy/Laparotomy & $14(5.1)$ \\
\hline Ovarian detorsion/Laparotomy & $3(1.1)$ \\
\hline Sacrohysteropexy & $3(1.1)$ \\
\hline Ovarian Cystectomy/Laparotomy & $2(0.7)$ \\
\hline Anteroposterior repair+perineoplasty & $1(0.4)$ \\
\hline Radical Hysterectomy+BSO+BPPLND & $1(0.4)$ \\
\hline $\mathrm{TAH}$ & $46(16.7)$ \\
\hline TAH + Bilateral Salpingooophorectomy (BSO) & $69(25.1)$ \\
\hline $\mathrm{TAH}+\mathrm{BSO}+\mathrm{BURCH}$ & $1(0.4)$ \\
\hline Vaginal Hysterectomy & $26(9.5)$ \\
\hline Total Laparoscopic Hysterectomy & $29(10.5)$ \\
\hline Unilateral Salpingooophorectomy/Laparoscopy & $14(5.1)$ \\
\hline Ovarian cystectomy / Laparoscopy & $24(8.7)$ \\
\hline Trans-vaginal-tape operation & $3(1.1)$ \\
\hline Staging surgery & $5(1.8)$ \\
\hline \multicolumn{2}{|l|}{ Type of Anesthesia, number, \% } \\
\hline General Anesthesia & $253(92.0)$ \\
\hline Regional Anesthesia & $22(8.0)$ \\
\hline \multicolumn{2}{|l|}{ Transfusion, number, \% } \\
\hline No & $244(88.7)$ \\
\hline Yes & $31(11.3)$ \\
\hline Hospital Stay Duration, median (range) & $4(3-29)$ \\
\hline \multicolumn{2}{|l|}{ Complication, number, $\%$} \\
\hline Postoperative fever & $2(0.7)$ \\
\hline Bowel injury & $1(0.4)$ \\
\hline Cuff hematoma & $7(2.5)$ \\
\hline Opening incision & $1(0.4)$ \\
\hline Surgical site infection & $2(0.7)$ \\
\hline Bladder injury & $2(0.7)$ \\
\hline Bladder atony & $1(0.4)$ \\
\hline \multicolumn{2}{|l|}{ Postoperative SARS-CoV-2 PCR, number, \% } \\
\hline Negative & $274(99.6)$ \\
\hline Positive & $1(0.4)$ \\
\hline
\end{tabular}

MTRB: Medical treatment-resistant bleeding, TAH: Total abdominal hysterectomy 
though there was no need for intensive care. The other two patients recovered completely at home and were operated on in the following months. The time from the first SARS-CoV-2 PCR positive test to the first negative test was recorded as the recovery time. (Table III).

One $(0.4 \%)$ patient was found SARS-CoV-2 positive 30 days postoperatively. The COVID-19 diagnosis of this patient was confirmed on the 30th day following the operation and no need for intensive care. She was followed up at home and received favipiravir/hydroxychloroquine treatment. On the seventh day after the diagnosis, the PCR test became negative and the patient completely recovered. The patient stated that on the post-operative $20^{\text {th }}$ day, she was in contact with COVID-19.

As a result, we calculated the perioperative SARS-CoV-2 positivity rate as $1.4 \%$ (276 surgeries were planned and 4 pa- tients were diagnosed with COVID-19) and postoperative SARS-CoV-2 positivity rate as $0.4 \%$.

Nine patients had been diagnosed with COVID-19 at various times before the surgery date. The patients' age, additional diseases, type of surgery, duration of hospital stay, intensive care need, medical treatment, recovery time, and postoperative complications are shown in table IV.

The patients had been informed that they were followed at home after the diagnosis and they recovered completely. None of them had needed intensive care. Duration of complete recovery was recorded as the time from the onset of symptoms to the end of them. In the asymptomatic patient \#1, this time was considered as the time from the first SARS-CoV-2 PCR positive test to the first negative test and the case was not delayed due to its urgency. None of these patients developed

Table III: Patients whose surgery was canceled on the pre-operative day 1 after SARS-CoV-2 PCR positivity was confirmed.

\begin{tabular}{|c|c|c|c|c|c|c|c|}
\hline Patient & $\begin{array}{l}\text { Age } \\
\text { (years) }\end{array}$ & $\begin{array}{l}\text { Additional } \\
\text { Disease }\end{array}$ & $\begin{array}{l}\text { Pre-op } \\
\text { PCR }\end{array}$ & $\begin{array}{l}\text { Intensive Care } \\
\text { Unit Admission }\end{array}$ & Treatment & Progress & $\begin{array}{l}\text { Recovery } \\
\text { Time }\end{array}$ \\
\hline 1 & 50 & Hypothyroidism & Positive & No & $\begin{array}{l}\text { Favipiravir } \\
\mathrm{HCQ}\end{array}$ & Complete recovery & 18 days \\
\hline 2 & 54 & No & Positive & No & $\begin{array}{l}\text { Favipiravir } \\
\mathrm{HCQ}\end{array}$ & Complete recovery & 12days \\
\hline 3 & 54 & No & Positive & No & $\begin{array}{l}\text { Favipiravir } \\
\mathrm{HCQ}\end{array}$ & Exitus on the 5th day after diagnosis & - \\
\hline
\end{tabular}

HCQ: Hydroxychloroquine

Table IV: Patients operated on with a history of COVID-19.

\begin{tabular}{|c|c|c|c|c|c|c|c|c|c|}
\hline Patient & $\begin{array}{l}\text { Age } \\
\text { (years) }\end{array}$ & $\begin{array}{l}\text { Additional } \\
\text { Disease }\end{array}$ & $\begin{array}{l}\text { Type of } \\
\text { surgery }\end{array}$ & $\begin{array}{l}\text { Hospital } \\
\text { Stay } \\
\text { Duration } \\
\text { (day) }\end{array}$ & $\begin{array}{l}\text { Time between } \\
\text { Covid-19 } \\
\text { diagnosis and } \\
\text { surgery }\end{array}$ & $\begin{array}{l}\text { Intensive } \\
\text { Care Unit } \\
\text { admission }\end{array}$ & $\begin{array}{l}\text { Medical } \\
\text { Treatment }\end{array}$ & $\begin{array}{l}\text { Recovery } \\
\text { time (days) }\end{array}$ & $\begin{array}{l}\text { Post-operative } \\
\text { complication }\end{array}$ \\
\hline 1 & 53 & Hypertension & $\mathrm{TAH}+\mathrm{BSO}$ & 4 & 5 & No & No & 5 & No \\
\hline 2 & 48 & Hypertension & $\mathrm{TAH}+\mathrm{BSO}$ & 4 & 30 & No & No & 14 & No \\
\hline 3 & 68 & No & $\mathrm{VAH}+\mathrm{BS}$ & 4 & 33 & No & Favipiravir & 12 & No \\
\hline 4 & 54 & No & TLH+BSO & 4 & 190 & No & $\begin{array}{l}\text { HCQ } \\
\text { Enoxaparine } \\
\text { sodium }\end{array}$ & 8 & No \\
\hline 5 & 65 & Hypertension & $\mathrm{VAH}+\mathrm{BS}$ & 3 & 120 & No & $\begin{array}{l}\text { Favipiravir } \\
\text { Enoxaparine } \\
\text { sodium }\end{array}$ & 10 & No \\
\hline 6 & 34 & No & USO & 3 & 33 & No & No & 10 & No \\
\hline 7 & 52 & Hypertension & TLH+BSO & 3 & 85 & No & $\begin{array}{l}\text { Favipiravir } \\
\mathrm{HCQ} \\
\text { Enoxaparine } \\
\text { sodium }\end{array}$ & 12 & Cuff hematoma \\
\hline 8 & 51 & No & $\mathrm{TLH}+\mathrm{BSO}$ & 4 & 40 & No & Favipiravir & 10 & No \\
\hline 9 & 52 & Hypertension & TLH+BSO & 4 & 90 & No & Favipiravir & 14 & No \\
\hline
\end{tabular}

TAH+BSO: Total abdominal hysterectomy+Bilateral salpingo-oophorectomy, VAH+BSO: Vaginal hysterectomy+Bilateral salpingo-oophorectomy, TLH+BSO: Total laparoscopic hysterectomy+Bilateral salpingo-oophorectomy, USO: Unilateral salpingo-oophorectomy, HCQ: Hydroxychloroquine 
intra-operative, post-operative complications related to other systems, especially the respiratory system. The hospitalization period did not prolong. The patient, who had a history of COVID-19, developed a vaginal cuff hematoma that did not require hospitalization (Table IV)

Due to the increasing number of patients coming to the clinic, the number of operations performed between March 11, 2020, and August 30, 2020, was 96, while the number of operations between September 1, 2020, and December 31, 2020, was 179 .

In this process, a total of 107 physicians, including 3 lecturers, 19 specialist doctors, and 85 assistant doctors, worked in our clinic alternately, two of these physicians (1.8\%) were diagnosed with COVID-19 and recovered completely without the need for intensive care.

\section{Discussion}

In our study, we aimed to calculate the perioperative/postoperative SARS-CoV-2 positivity rate in patients who were operated on/ planned to be operated on in our clinic. Based on the preoperative SARS-CoV-2 PCR test results and postoperative follow-up data, we calculated the postoperative SARSCoV-2 positivity rate as $0.4 \%$ and the perioperative SARSCoV-2 positivity rate as $1.4 \%$. In addition, we noted that 107 physicians worked in our clinic alternately and only two (1.8\%) were diagnosed with COVID-19 during this period.

On 30 December 2020, the Ministry of Health, Türkiye announced the number of tests in our country as 24.504 .567 and the number of cases as 2.208.652 (9\%); considering this the rate of SARS-CoV-2 positivity in our patients and employees is lower than the general population. According to Yang et al. in a study on 33 people, the incidence of COVID-19 in women who underwent gynecological cancer surgery was reported to be $6.1 \%$ (16); similarly, Ali Ayhan et al. in another retrospective study in which 688 oncologic surgery patients were analyzed, the perioperative COVID-19 incidence was found to be $6.7 \%(17)$. The low incidence in our study compared to the general population and these studies were primarily attributed to the patient population we tested, was asymptomatic. While the tests performed on the general population are symptombased and diagnostic, the preoperative tests are screening tests and performed in the asymptomatic patient group. Screening tests with RT-PCR for SARS-CoV-2 are recommended for all potential surgical procedures (18). In our clinic, screening tests were performed as soon as the patients were admitted to the hospital. Patients who were diagnosed with COVID-19 preoperatively were evaluated as multidisciplinary and discharged immediately. It was thought that screening tests would reduce the transmission in the hospital and the social isolation of the patients was provided until the results came out. Additionally, the use of personal protective equipment, social isolation rules, restriction of visitors, regulation of physical and hygienic conditions in accordance with infection prevention recommendations may have reduced transmission.

In a study by Polat et al on 200 patients who had undergone gynecological cancer surgery, no patient was diagnosed with COVID-19, but suspicious computed tomography findings were found in two patients (19). In another study by Alimoglu et al, in 39 patients who were operated on with a diagnosis of cancer, none of the patients had COVID-19 symptoms in the postoperative period (20). Our study and similar studies like this suggest that treatment procedures performed in accordance with health policy strategies and rules are safe and operations do not adversely affect the pandemic.

Hospitalization and hospitals are considered independent risk factors for SARS-CoV-2 infection (21). In our study, it was observed that hospitalization did not increase the incidence of COVID-19 compared to the general population. This situation can be attributed to educating and raising awareness of patients about contact isolation and personal hygiene.

In our study, mortality developed in a single patient diagnosed with COVID-19 pre-operatively, and no intensive care unit was needed for any patient. The patient who died had been diagnosed one day before the planned operation and was discharged after the decision to be followed at home. The treatment had been arranged multidisciplinary. The other two patients who were diagnosed with COVID-19 preoperatively, recovered completely and their operations were postponed to a later date. Importantly, healthcare workers who had contact with patients diagnosed with SARS-CoV-2 infection were not diagnosed with COVID-19 in the following period and did not have suspicious symptoms.

SARS-CoV-2 PCR positivity was detected postoperatively, on the 30th postoperative day, in only one patient. During the follow-up, the patient stated that the source of the disease was a relative who was diagnosed with COVID-19 and was treated in intensive care. Considering that the incubation period of SARS-CoV-2 infection is approximately two weeks (22), the infection, diagnosed on the 30 th postoperative day may be community-acquired.

In our study, nine patients, who were previously diagnosed with COVID-19 and whose treatments were completed at home, were operated on due to negative preoperative SARSCoV-2 PCR results. In these patients, no intraoperative or postoperative complications related to other systems, especially the respiratory system, have not developed. The hospitalization period of the patients did not prolong, and hospitalization was not required in the patient who developed vaginal cuff hematoma in the early postoperative period. Similar to our study, Cai et al. in a single-center retrospective study, eight COVID-19 patients and 22 non-infected patients who underwent emergency abdominal surgery in Wuhan, China were analyzed and no difference was noted in postoperative 
recovery and survival between mildly infected or asymptomatic patients. Therefore, the necessity of postponing operations has been questioned (23).

Postponement of non-urgent surgical services will inevitably cause a significant backlog. This situation may subsequently cause a burden on surgical capacity as well as cause excessive stress and anxiety for patients personally (24). Throughout our study, there were patients whose operations were delayed by regulating their medical treatments but were ultimately operated on due to treatment-resistant bleeding and pain. When the distribution of the patients by months is examined, the number of operations performed on March 11, 2020-August 30, 2020 was 96, while the number of operations performed on September 1, 2020-December 31, 2020 was 179. During this period, four patients who complained of urinary incontinence and whose operations were postponed due to not being urgent stated that their quality of life was seriously impaired and refused to postpone their surgery and was operated on. Thousands of patients worldwide lack surgical access and expect to undergo elective and emergency surgical procedures. These patients will undoubtedly experience increased morbidity and mortality as a side effect of the COVID-19 pandemic (25). Postponing non-urgent surgical procedures may cause some surgical procedures to fall into the emergency category over time. Based on the fact that the epidemic will continue, although it is alleviated, planned surgical interventions should be started gradually (13). Various plans should be made to manage the future demand due to delayed surgical procedures.

In addition to all these, the reorganization of healthcare systems due to the increasing burden of COVID-19 will create disruptions in medical education. There is a need for regulations so that students can protect their clinical skills and knowledge (26). The fact that our hospital is a well-established hospital located in the capital Ankara and the high number of emergency and non-delayed cases did not cause any problems in education and research. Nevertheless, reorganization of surgical procedures that are deemed to be postponed may be considered.

As a result, it has been observed that the surgical procedures we perform do not increase the SARS-CoV-2 transmission compared to the general population, as long as the patients and employees comply with infection control measures. This result suggests that hospitalization and surgical procedures will not adversely affect the COVID-19 pandemic unless hospitals have technical inadequacy and capacity problems. For this reason, we think that surgeries that are deemed to be postponed should be reconsidered to avoid accumulation in health systems and to avoid urgency in postponed elective surgeries.

\section{Declarations}

Acknowledgment: There is no financial support for this study.
We are grateful to all participants and their families who spent their precious time and participated in this research program. We are also thankful for the tireless efforts of the research team members.

Funding: There is no funding for this study.

Competing interests: The authors declare that they have no competing interests.

Ethics approval and consent to participate: All participants signed informed written consent before being enrolled in the study. The study was reviewed and approved by the ethics committee of Etlik Zubeyde Hanim Gynecology Training and Research Hospital (Ethics approval reference number:2021/64 date:09.06.2021). All procedures were performed according to the Declaration of Helsinki.

Availability of data and materials: The data supporting this study is available through the corresponding author upon reasonable request.

Authors'contributions: $Y U, V K$, and GRT raised the presented idea. YU and VK designed the study. VK conducted the analyses. GRT and EU developed the first draft of the manuscript. All authors contributed to the writing of the paper, and have read and approved the final manuscript. GRT, TK, SEA conducted the population study, analyzed and interpreted the data, and drafted the manuscript. GRT and VK participated in data analysis, interpretation, and draft revision. MAA, ARD, EEE, and SA participated in data collection and result interpretation. GRT, EEE, and SA assisted with data collection and analysis. YU, VK, GRT designed the study and critically revised the manuscript. All authors read and approved the final manuscript.

\section{References}

1. Wuhan Municipal Health Commission (2019) Report of clustering pneumonia of unknown etiology in Wuhan City. Available from: http://wjw.wuhan.gov.cn/front/ web/showDetail/2019123108989 [in Chinese] (accessed 10 April 2020)

2. Park SE. Epidemiology, virology, and clinical features of severe acute respiratory syndrome -coronavirus-2 (SARSCoV-2; Coronavirus Disease-19). Clin Exp Pediatr. 2020;63(4):119-24. Doi: 10.3345/cep.2020.00493.

3. World Health Organization Clinical management of severe acute respiratory infection when Novel coronavirus $(\mathrm{nCoV})$ infection is suspected [EB/OL] Available from: https://www.who.int/publications/i/item/10665-332299

4. World Health Organization. WHO Director-General's opening remarks at the media briefing on COVID-19 - 11 March 2020 [Internet]. Geneva (Switzerland): World Health Organization; 2020 [cited 2020 Mar 11]. Available from: https://www.who.int/director-general/speeches/detail/who-director-general-s-opening-remarks-at-themedia-briefing-on-covid-19-11-march-2020

5. Legido-Quigley H, Asgari N, Teo YY, Leung GM, Oshitani H, Fukuda K, et al. Are high-performing health 
systems resilient against the COVID-19 epidemic? Lancet. 2020;395(10227):848-50. Doi: 10.1016/S0140-67 36(20)30551-1.

6. Guidance for health system contingency planning during widespread transmission of SARS-CoV-2with high impact on healthcareservices. Available from: https://www. ecdc.europa.eu/en/publications-data/guidance-health-system-contingency-planning-during-widespread-transmission-sars

7. Interim Guidance for Healthcare Facilities: Preparing for Community Transmission of COVID-19 in the United States. Available from: https://www.cdc.gov/coronavirus/2019-ncov/hcp/us-healthcare-facilities.html

8. COVID-19: Recommendations for Management of Elective Surgical Procedures. March 13, 2020. Available from: https://www.facs.org/covid-19/clinical-guidance/ elective-surgery

9. Spinelli A, Pellino G. COVID-19 pandemic: perspectives on an unfolding crisis. Br J Surg. 2020;107(7):785-7. Doi: 10.1002/bjs. 11627 .

10. American College of Surgeons. COVID19 and Surgery. COVID-19: Elective Case Triage Guidelines for Surgical Care Online March 24, 2020. Available from: https:// www.facs.org/covid19/clinical-guidance/elective-case

11. Guidelines to Help Countries Maintain Essential Health Services during the COVID-19 Pandemic. World Health Organization Department of Communications; 2020. Available from: https://www.who.int/southeastasia/news/ detail/06-08-2020-maintain-essential-health-services-during-covid-19-response-who

12. https://ohsad.org/wp-content/uploads/2020/06/COVID_ 19_Normallesme_Ustyazi.pdf 2020-03-17

13. Saglik Kurumlarinda Calisma Rehberi Ve Enfeksiyon Kontrol Onlemleri Kilavuzu Available from: https:// COVID19.saglik.gov.tr/TR-66532/saglik-kurumlarindacalisma-rehberi-ve-enfeksiyon-kontrol-onlemleri.html

14. Adhikari SP, Meng S, Wu YJ, Mao YP, Ye RX, Wang QZ, et al. Epidemiology, causes, clinical manifestation and diagnosis, prevention and control of coronavirus disease (COVID-19) during the early outbreak period: a scoping review. Infect Dis Poverty. 2020;9(1):29. Doi: 10.1186/s40249-020-00646-x.

15. Xie X, Zhong Z, Zhao W, Zheng C, Wang F, Liu J. Chest CT for typical coronavirus disease 2019 (COVID-19) pneumonia: relationship to negative RT-PCR testing. Radiology. 2020;296(2): E41-E45. Doi:10.1148/radio:1. 2020200343.

16. Yang S, Zhang Y, Cai J, Wang Z. Clinical characteristics of COVID-19 after gynecologic oncology surgery in three women: a retrospective review of medical records. Oncologist. 2020;25(6):e982-e985. Doi: 10.1634/theoncologist.2020-0157.

17. Ayhan A, Oz M, Topfedaisi Ozkan N, Aslan K, Altintas $\mathrm{MI}$, Akilli $\mathrm{H}$, et al. Perioperative SARS-CoV-2 infection among women undergoing major gynecologic cancer surgery in the COVID-19 era: A nationwide, cohort study from Türkiye. Gynecol Oncol. 2021;160(2):499-505. Doi: 10.1016/j.ygyno.2020.11.014.

18. Bhatla N, Singhal S. The COVID-19 Pandemic and 1mplications for gynaecologic cancer care. Indian $\mathrm{J}$ Gynecol Oncol. 2020;18(2):48. Doi: 10.1007/s40944020-00395-7.

19. Dursun P, Dervisoglu H, Daggez M, Turan T, Kiliç F, Tekin ÖM, et al. Performing gynecologic cancer surgery during the COVID-19 pandemic in Türkiye: A multicenter retrospective observational study. Int $\mathrm{J}$ Gynaecol Obstet. 2020;151(1):33-8. Doi: 10.1002/ijgo.13296.

20. Alimoglu O, Erol CI, Kilic F, Baysal H. Cancer surgery during the Covid-19 pandemic in Türkiye. Int J Surg. 2020;79:54-5. Doi: 10.1016/j.ijsu.2020.05.040.

21. Yu J, Ouyang W, Chua MLK, Xie C. SARS-CoV-2 Transmission in patients with cancer at a tertiary care hospital in Wuhan, China. JAMA Oncol. 2020;6(7):1108-10. Doi: 10.1001/jamaoncol.2020.0980.

22. Zhang L, Zhu F, Xie L, Wang C, Wang J, Chen R, et al. Clinical characteristics of COVID-19-infected cancer patients: a retrospective case study in three hospitals within Wuhan, China. Ann Oncol. 2020;31(7):894-901. Doi: 10.1016/j.annonc.2020.03.296.

23. Cai M, Wang G, Zhang L, Gao J, Xia Z, Zhang P, et al. Performing abdominal surgery during the COVID-19 epidemic in Wuhan, China: a single-centred, retrospective, observational study. Br J Surg. 2020;107(7):e183-e185. Doi: 10.1002/bjs.11643.

24. Herrod PJJ, Adiamah A, Boyd-Carson H, Daliya P, ElSharkawy AM, Sarmah PB, et al. Winter cancellations of elective surgical procedures in the UK: a questionnaire survey of patients on the economic and psychological impact. BMJ Open. 2019;9(9):e028753. Doi: 10.1136/bmj open-2018-028753.

25. Søreide K, Hallet J, Matthews JB, Schnitzbauer AA, Line PD, Lai PBS, et al. Immediate and long-term impact of the COVID-19 pandemic on delivery of surgical services. Br J Surg. 2020;107(10):1250-61. Doi: 10.1002/bjs.11670.

26. Mian A, Khan S. Medical education during pandemics: a UK perspective. BMC Med. 2020;18(1):100. Doi: 10.1186/s12916-020-01577-y. 